\title{
A new strategy for the seismic assessment of existing RC buildings
}

\author{
Edoardo Cosenza, Gaetano Manfredi and Gerardo M. Verderame \\ Dipartimento di Analisi e Progettazione Strutturale, Università degli Studi di Napoli «Federico II», Napoli, Italy
}

\begin{abstract}
This paper presents a new strategy for the seismic assessment of existing Reinforced Concrete (RC) buildings. The proposed method is based on a two steps approach. A field survey of some buildings is first developed to record their geometrical and mechanical characteristics; such survey is then enriched with information based on regulations and practical rules used during construction: the result of this step is the definition of homogeneus classes of buildings representing typical structures. The second step is based on the assessment of the seismic capacity of these structures using both refined models and parametric analysis: the outcomes can be extended to the defined classes to obtain vulnerability maps. A first application of the proposed strategy was made in Catania and the results of that study on an urban area, characterized by RC buildings constructed in the ' 60 s and ' 70 s without seismic provisions, are briefly presented.
\end{abstract}

Key words seismic assessment - vulnerability buildings - concrete - steel

\section{Introduction}

The reduction of the seismic risk of existing structures has an high social and economical impact in Italy; in fact the $43 \%$ of the Italian territory is classified as exposed to seismic risk and, within this portion, only the $40 \%$ of structures have been designed according to seismic guidelines (De Marco et al., 2000). The majority of the Italian seismic areas were only officially recognized in the national regulation after 1981 (fig. 1). Most of its buildings dates back to the late '60s and to the sudden urbanization of that period. In 1961, 10.7 million apartments were counted, increasing to 22.5 millions in 1981 ; this

Mailing address: Dr. Edoardo Cosenza, Dipartimento di Analisi e Progettazione 5Strutturale, Università degli Studi di Napoli «Federico», Via Claudio 21, 80125 Napoli, Italy; e-mail: cosenza@unina.it number increased of only 4.5 million between 1981 and 1998 (Censis, 1999).

The seriousness of this potential risk is increased considering that, unlike the majority of European countries, Italian urban planning politicies tend to preserve the landscape, avoiding the continuous reconstruction of buildings. Moreover, in Italy the quality of the construction process has been poor in comparison with other European countries, mainly for structures built from 1945 to 1980 . This situation is due to illegal construction carried out with unsatisfactory criteria and poor quality materials. In addition, the entire design and construction process has been characterized by a poor quality control; rules and procedures relating to checks during construction have generally been neglected in the past.

In this context, the development of a rational procedure for the seismic assessment of existing buildings is a priority toward the definition of actions required to reduce seismic risk, and the selection of the methodology for the analysis represents a crucial aspect. The idea of using for the buildings an approach that is different from 


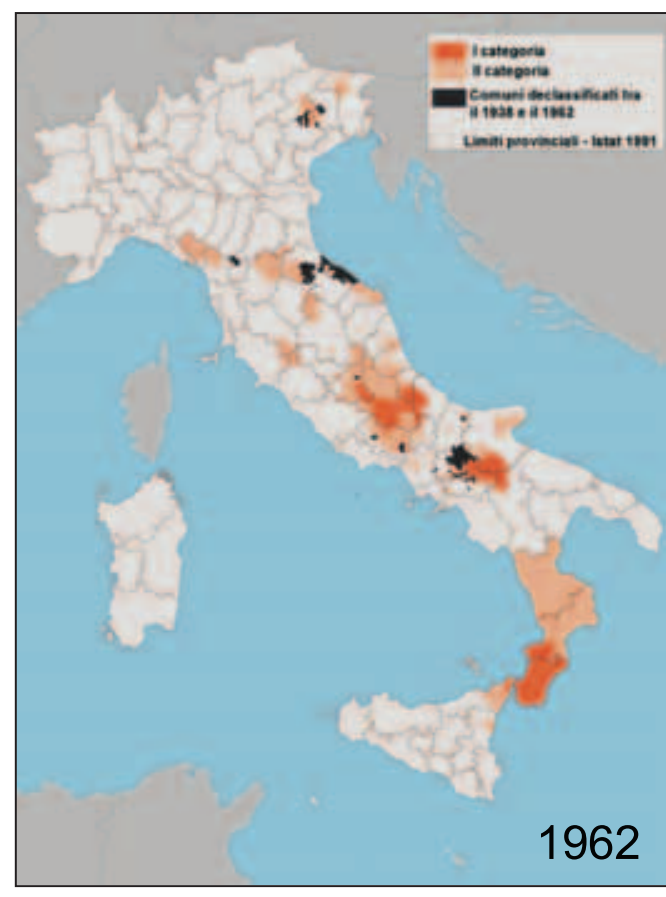

(a)

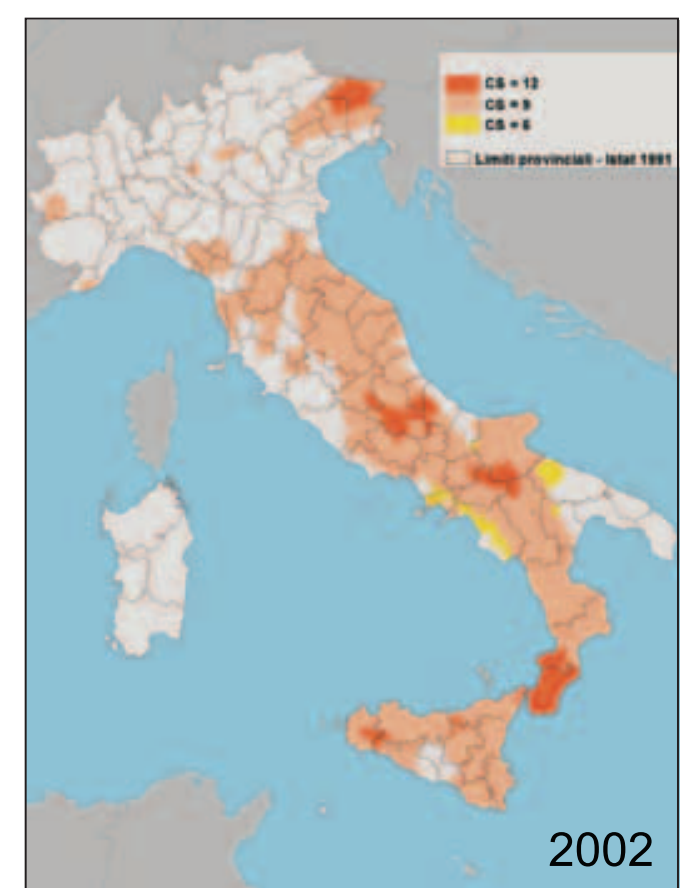

(b)

Fig. 1. Areas exposed to seismic risk in the Italian classification.

those adopted for vulnerability studies of urban areas could be acceptable, even though not mandatory, as both goals and level of approximation may not be the same. The EC8 (Eurocode $8,1995)$ suggests the following assessment methods for vulnerability analyses:

- Level I: less than one hour of analysis, focusing only on simple information such as the building age and the structural configuration.

- Level II: more detailed and longer than Level I (about half day of analysis per building) including also some geometrical measurements.

- Level III: much more accurate than the first two and including mechanical measurements.

Methods of fast assessment are generally preferred for the risk analysis in large areas (even with little information), whereas detailed methods are used for the evaluation of the seismic capacity of single buildings. The fast assessment is based on the observation of those characteristics of potential seismic damage; since the method is very conservative, it does not allow a detailed screening of all the most vulnerable buildings. Depending on the structural configuration and the seismicity of the area, a vulnerability grade is associated to each building. Such preliminary value is then changed based on other vulnerability properties characterizing the building and considered highly significant (i.e. irregularities in plan or elevation, unsatisfactory torsional behavior, soft story, etc.) (Braga et al., 1982). The need for more detailed investigations is then deduced based on the total grade (representing an index of potential damage) and on the plan extension which gives a rough idea of the occupancy level. Such methods allow for risk assessment on a large scale and are characterized by a high level of uncertainties. The 
philosophy for its use suggested by late codes (BIA, 1996; ATC, 1996) is to consider all of them as pre-screening methods toward the definition of the most appropriate procedure of analysis: those buildings showing deficiencies in both material and structural sides are then studied with more detailed methods.

A more accurate approach for buildings was recently proposed by Calvi (1999). It was derived from concepts and outcomes of detailed analyses on existing buildings and is based on the evaluation of allowable interstory drifts for each structural configuration. The method is analytical and needs few input data. Despite these advantages, the uncertanites on the results are acceptable for large scale evaluations, while they are not adequate for single building assessment.

This paper presents a new strategy for the seismic assessment of existing RC buildings. The proposed method is based on a two-step approach. A field survey of geometrical and mechanical buildings characteristics is first developed and enriched with information based on regulations and practise rules used during construction: the result of this step is the definition of homogeneus classes of buildings representing typical structures. The second step is based on the assessment of the seismic capacity of these structures using both refined models and parametric analysis: the outcomes of this analysis can be extended to the defined classes of buildings to obtain vulnerability maps.

\section{A flow chart of the strategy}

The proposed new strategy of assessment is devoted to the vulnerability analysis of urban areas; it is based on some steps aimed at collecting basic information for the assessment of buildings and on the use of methodologies that are typical of the detailed analysis (fig. 2).

The step related to the data acquisition is crucial since its unknowns could play a significant role in the final evaluation. A typical form allowing for recording the current status of a single building (structural system, configuration, materials) should be defined; a database on the mechanical properties of materials used in construction and a comprehensive recognition of rules and regulations in force when the building was constructed should also be carried out in order to have a set of information to use not only to implement but also to check acquired data.

The survey form can be summarized as follows:

- Building selection depending on location and construction date.

- Properties concerning shape and size such as plan dimensions or number of storeys.

- Properties related to the structural configuration and type of elements such as columns, beams, stairs, slabs, etc.

- Characteristics of non structural elements such as infills.

- Level of observed damage.

- Condition of the building compared to the surrounding environment and buildings.

The information, summarized in the proposed form, can be integrated by data obtained by checking libraries and technical offices, or interviewing contractors and engineers: all these data define design criteria and general rules for the details.

The analysis of morphological and structural parameters will define homogeneous classes of buildings having the same morphology, structural configuration, number of storeys, materials and quality of construction. Such classes are further specified considering ranges of construction ages characterized by the same code requirements, design criteria and pratical rules.

Within each category a representative virtual building is constructed based on the data obtained: in fact, its mechanical and geometrical properties are those of all buildings of that category, while its structural details are defined using the general rules previously classified for age and quality of construction.

The specific study of existing buildings (among those already examined) which are similar to the representative construction confirms the dimensional properties of the structural elements as well as the reinforcement and the details (i.e. beam-column joints, etc.) characterizing the virtual structure.

Finally, each structural configuration, representative of a certain class, is studied by two different approaches to assess the seismic capacity of that class: the first is based on a parametric 


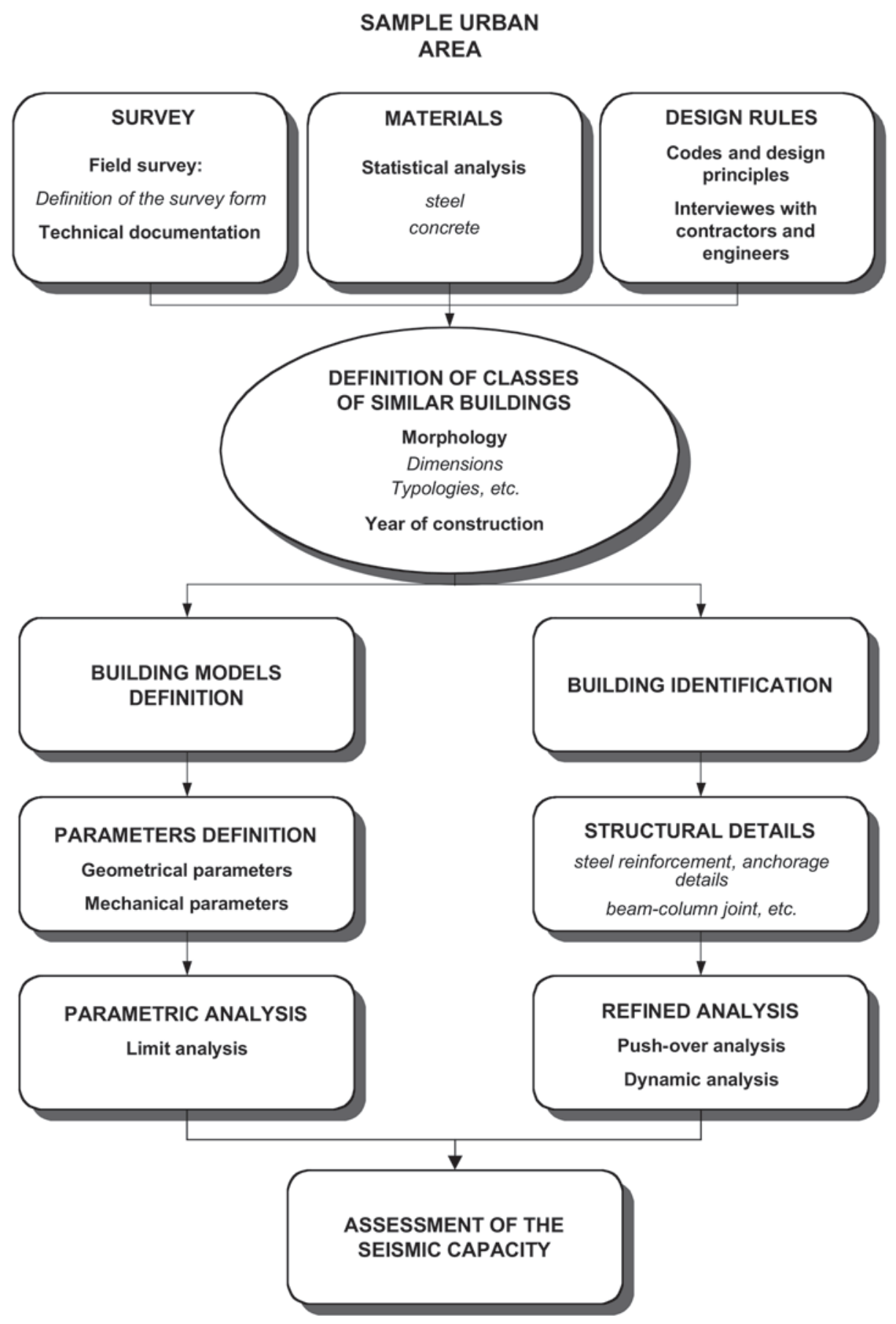

Fig. 2. Flow chart of the assessment strategy. 
analysis with simplified methods (i.e. limit analysis), the second uses the usual methods of detailed analysis (push-over or non-linear dynamic analysis). The parametric analysis starts from the representative building varying dimensional and mechanical properties within assigned ranges.

The outcomes can be statistically treated in order to obtain the vulnerability characteristics of each class of structures needed to define scenarios of seismic risk.

\section{The materials database}

A first step of the proposed strategy for the seismic assessment of the existing RC structures is the development of a statistical database on the mechanical properties of concrete and steel used.

For concrete, the source of the analysis was the Official Laboratory of the Department of Construction Sciences of the «Federico II» University of Naples; test data on concrete cubes performed during the decade 1960-1970 were considered (Verderame et al., 2001a). The data collection and the statistical processing were

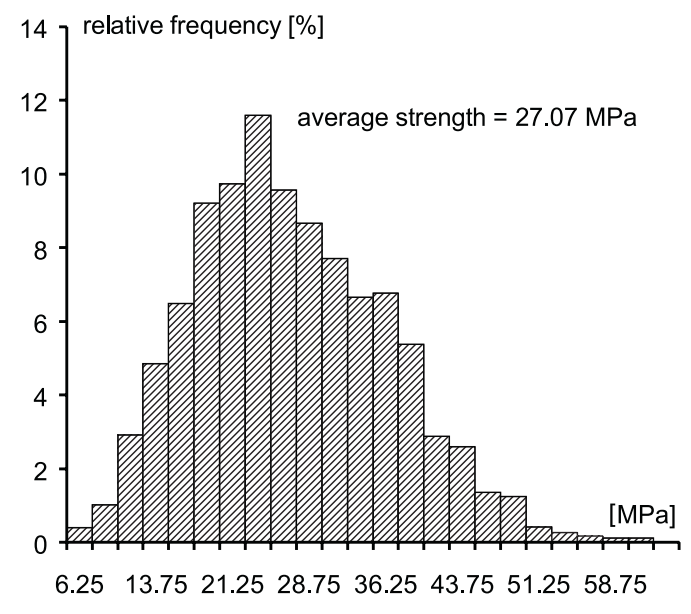

(a) carried out on a population of strength having the same cement content equal to $300 \mathrm{~kg} / \mathrm{m}^{3}$. The cement title was ignored since it was almost constant; the most frequent titles in the period $1960-1966$ are $600 \mathrm{~kg} / \mathrm{cm}^{2}$ and $670 \mathrm{~kg} / \mathrm{cm}^{2}$, whereas between 1967 and 1970 the titles 730 $\mathrm{kg} / \mathrm{cm}^{2}$ and 325 and $425 \mathrm{~kg} / \mathrm{cm}^{2}$ (still existing) become common. The outcomes of the statistical analysis on the strength for 1960 and for the entire decade 1960-1970 are summarized below. Figure $3 \mathrm{a}, \mathrm{b}$ shows the diagram of frequencies for 1960 ; the average concrete strength of 1960 is equal to 27.07 MPa. Table I details shape and scatter indexes as well as other parameters characterizing the samples of 1960. In order to extend the validity of the results of 1960 , a statistical analysis of the data concerning the decade 19611970 was conducted.

Table I. Strength distribution of concrete in the year 1960.

\begin{tabular}{lcc}
\hline \hline Analyzed data & & 4850 \\
Average strength & {$[\mathrm{MPa}]$} & 27.07 \\
Standard deviation & {$[\mathrm{MPa}]$} & 9.41 \\
C.O.V. & & $34.76 \%$ \\
\hline
\end{tabular}

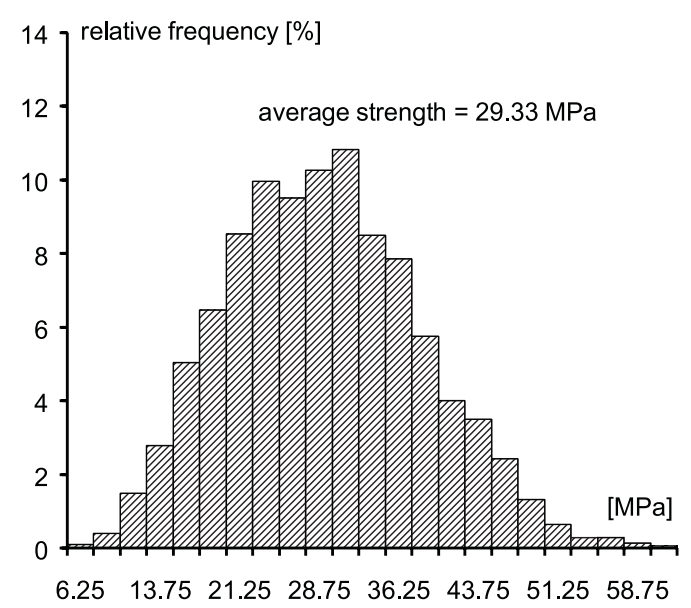

(b)

Fig. 3a,b. Concrete strength distribution (a) for the year 1960 and (b) for the decade 1960-1970. 
The results confirm the main indexes of position and dispersion obtained only in 1960 . Concerning the average concrete strength, the trend appears to be constant as the average within the decade is $29.33 \mathrm{MPa}$ compared to $27.07 \mathrm{MPa}$ recorded in 1960. Figure 3a,b shows the frequencies of the strength, while table II reports the main indexes of shape and dispersion.

A similar procedure was followed to define the types of steel produced and used during the decade 1960-1970 and to classify its mechanical properties: in this case, the results of tensile tests conducted during the reference period were considered (Verderame et al., 2001b).

The analyzed sample can be considered as representative of the entire area of Campania and of the Southern part of Italy. The data were classified according to the code valid during the '60 that distinguished three types of steel Aq. 42, Aq. 50 and Aq. 60 based on yielding stress, ultimate stress and ultimate elongation. Those three types of steel referred to special steel with ultimate stresses ranging between 42-50, 50-60 and $60-70 \mathrm{~kg} / \mathrm{mm}^{2}$, respectively.

Table II. Strength distribution of concrete in the decade 1960-1970.

\begin{tabular}{lcc}
\hline \hline Analyzed data & & 4955 \\
Average strength & {$[\mathrm{MPa}]$} & 29.33 \\
Standard deviation & {$[\mathrm{MPa}]$} & 9.08 \\
C.O.V. & & $30.96 \%$ \\
\hline
\end{tabular}

Table III. Mechanical properties of steel Aq. 42 in the year 1960 .

\begin{tabular}{lcccc}
\hline $\begin{array}{l}\text { Analyzed data: } \\
729\end{array}$ & $\begin{array}{c}f_{y} \\
{[\mathrm{MPa}]}\end{array}$ & $\begin{array}{c}f_{u} \\
{[\mathrm{MPa}]}\end{array}$ & $f_{u} / f_{y}$ & $A_{10 \phi}$ \\
\hline Average value & 325.4 & 467.1 & 1.440 & $28.8 \%$ \\
Max. value & 397.4 & 499.9 & 1.812 & $39.2 \%$ \\
Min. value & 265.0 & 420.1 & 1.096 & $20.0 \%$ \\
Standard dev. & 23.1 & 21.7 & 0.086 & 0.031 \\
C.O.V. & 0.071 & 0.047 & 0.060 & 0.107 \\
\hline
\end{tabular}

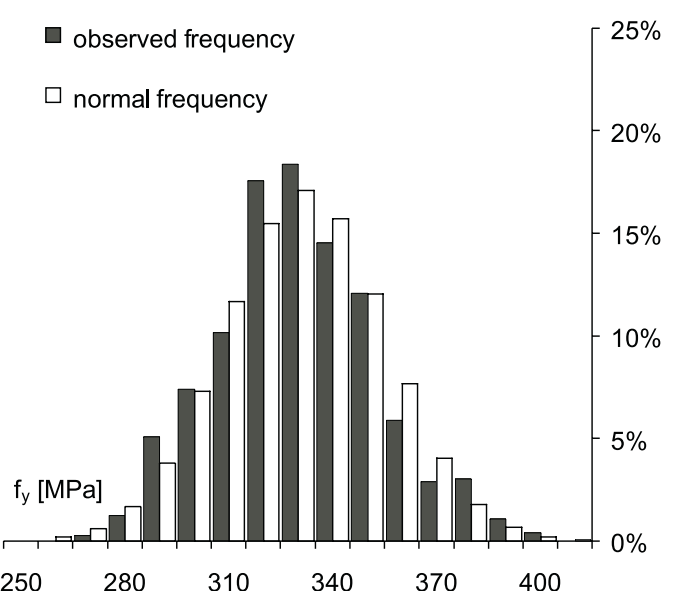

(a)

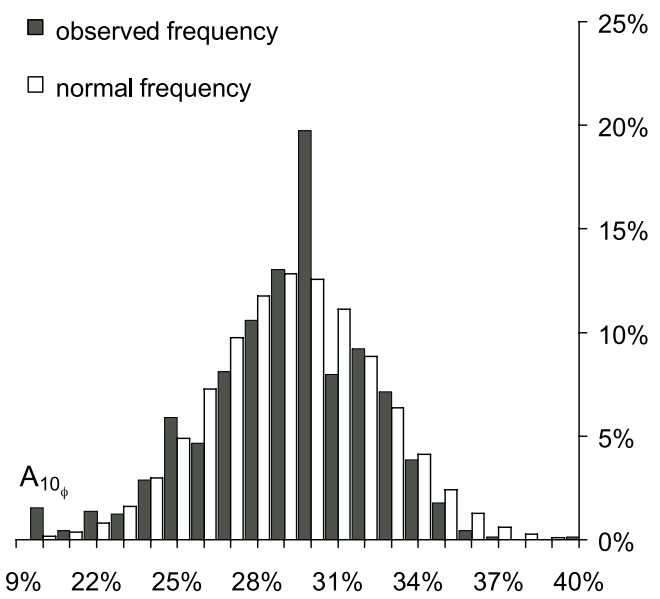

(b)

Fig. 4a,b. Steel properties distribution for the year 1960: a) yielding stress; b) ultimate elongation.

The Aq. 42 steel was the steel most adopted during the reference period; fig. $4 \mathrm{a}$, b shows the frequencies of its yielding stress and ultimate elongation; table III summarizes the main shape and dispersion indexes for the mechanical properties examined. 
The high ductility of this steel can be emphasized, showing an average strain hardening equal to 1.440 and an average ultimate elongation on 10 diameters equal to $28.81 \%$.

In order to extend the results on 1960, a statistical characterization of steel Aq. 42 was carried out for the period 1960-1970. 232 files were examined, recording geometrical (i.e. bar diameter) and mechanical (yielding and ultimate stress, ultimate elongation) parameters.

Such analysis confirmed the values obtained with reference to 1960 ; the investigated parameters were basically constant throughout the decade. The average yielding and ultimate stresses along the decade are $328.6 \mathrm{MPa}$ and $470.0 \mathrm{MPa}$, respectively, just slightly higher than those recorded in 1960 and equal to $325.4 \mathrm{MPa}$ and 467.1 MPa. Therefore, the strain hardening ratio remained constant throughout the decade. Table IV shows the main shape and dispersion indexes of mechanical properties of steel Aq. 42 used during the period 1961-1970.

\section{A numerical model for the seismic assessment of $\mathrm{RC}$ frames}

$\mathrm{RC}$ frames designed without seismic provisions have in many cases a structural behavior characterized by low available ductility and lack of strength hierarchy inducing undesirable global failure mechanisms. The lack of horizontal and vertical regularity and the high torsional deformation are also problems resulting in an unsatisfactory global behavior. Details such as low confinement levels or insufficient anchorage of rebars can also represent potential critical zones, characterized by brittle mechanisms and low available ductility (Cosenza and Manfredi, 1997).

In the case of the columns, the low confinement level (i.e. spacing of stirrups or presence of ties) can result in the flexural crisis at the bottom of columns located at low levels with instability of the compressive reinforcement, slippage of tensile rebars and crushing of the unconfined concrete.

Shear failure can occur in beams due to both insufficient steel reinforcement and increase in loads during the earthquake; for this specific
Table IV. Mechanical properties of steel Aq. 42 in the decade 1960-1970.

\begin{tabular}{lcccc}
\hline $\begin{array}{l}\text { Analyzed data: } \\
232\end{array}$ & $\begin{array}{c}f_{y} \\
{[\mathrm{MPa}]}\end{array}$ & $\begin{array}{c}f_{u} \\
{[\mathrm{MPa}]}\end{array}$ & $f_{u} / f_{y}$ & $A_{10 \phi}$ \\
\hline Average value & 328.6 & 470.0 & 1.436 & $29.1 \%$ \\
Max. value & 408.0 & 499.8 & 1.696 & $35.6 \%$ \\
Min. value & 260.0 & 422.0 & 1.158 & $20.0 \%$ \\
Standard dev. & 26.1 & 18.8 & 0.088 & 0.032 \\
C.O.V. & 0.079 & 0.040 & 0.061 & 0.111 \\
\hline
\end{tabular}

problem, the non-linear interaction between shear and bending strongly influences the structural behavior. Shear failure of short columns (i.e. stairs frames) can also be the cause of a brittle structural response.

The behavior of joints represents another critical issue due to the lack of appropriate detailing. In the case of smooth rebars, the absence of hooks at the end can result in the pull out of the rebars; exterior joints are the most critical, even though the same type of failure could also involve interior joints with lap splices. Shear failure of the panel can be observed if it is not confined and it is subjected to high shear stresses. In general, the frame deformation largely depends on the fixed end-rotation of the joint that is amplified in Gravity Load Designed (GLD) structures by high stresses in the reinforcement and poor anchorage.

In some cases, another important contribution to the strength of the frame can come from the infill walls. The interaction between infill walls and bare frame should be considered since brittle failures can be originated by the concentration of high stresses transferred from the infills to both joints and columns.

These remarks underline how many issues should be taken into account in the assessment of the seismic behavior of existing RC underdesigned frames. In general, all the brittle mechanisms can potentially play an important role; the models need to be able to predict them in order to provide reliable estimates of the seismic capacity. 
The push over analyses, used in the seismic assessment of RC existing structures, are carried out by a numerical tool developed at the University of Naples. This model is able to predict the main mechanisms influencing non linear behaviour of reinforced concrete frames in terms of behavior mechanisms and material properties (Cosenza et al., 2002a).

The beam-column element is characterised by spread plasticity and distributed cracking: it belongs to the fibre model family. The mechanical properties of the transverse section are evaluated by considering the constitutive laws of materials. The hypothesis of perfect bond between concrete and steel is removed and the stress-slip bond constitutive law is explicitly introduced. Such aspect allows for a more reliable assessment of the tension stiffening effect, for both smooth and deformed rebars, and avoids the approximations due to the assumption of the plastic hinge length.

For the column, it is possible to consider the variation of axial forces due to lateral loads, and the related effects in terms of sectional strength and deformation capacity. The beam-column joint plays a significant influence on the structural response, in terms of strength (i.e. shear failure of the panel or pull out of the rebars) and deformation, due to concrete cracking and slippage of rebars. The proposed model for beam-column joints allows the fixed end rotation to be computed taking into account the bond between concrete and steel and the behaviour of the hooks.

The influence of shear forces on the behaviour of the beams was modelled by Priestley et al. (1994); such model is based on a reduction of the shear strength depending on the local ductility, expressed in terms of curvature varying with a linear trend. The introduced model represents an improvement of Priestley's because it directly determines the sectional ductility at any step of the analysis and then evaluates the shear strength of those sections located in the plastic regions. Therefore, along with predicting ductile (i.e. flexural) and brittle (i.e. shear)

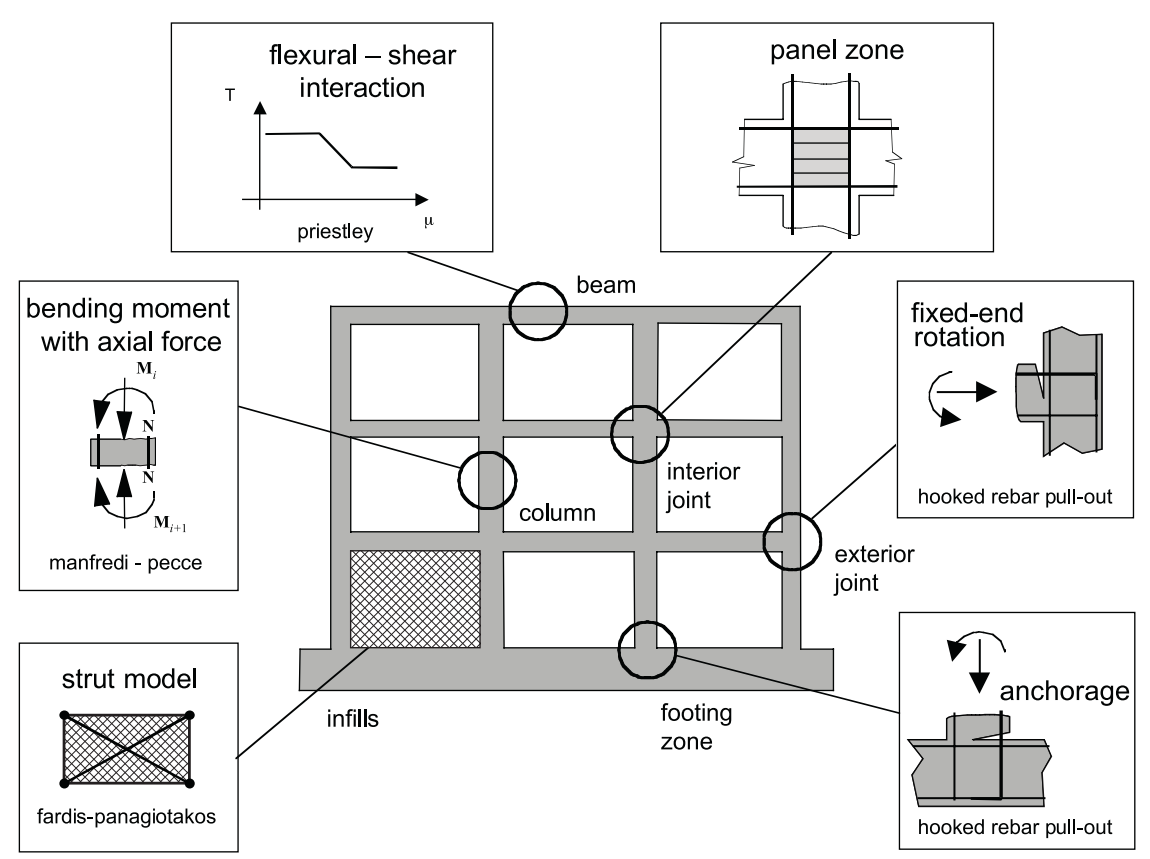

Fig. 5. RC frame modelling. 


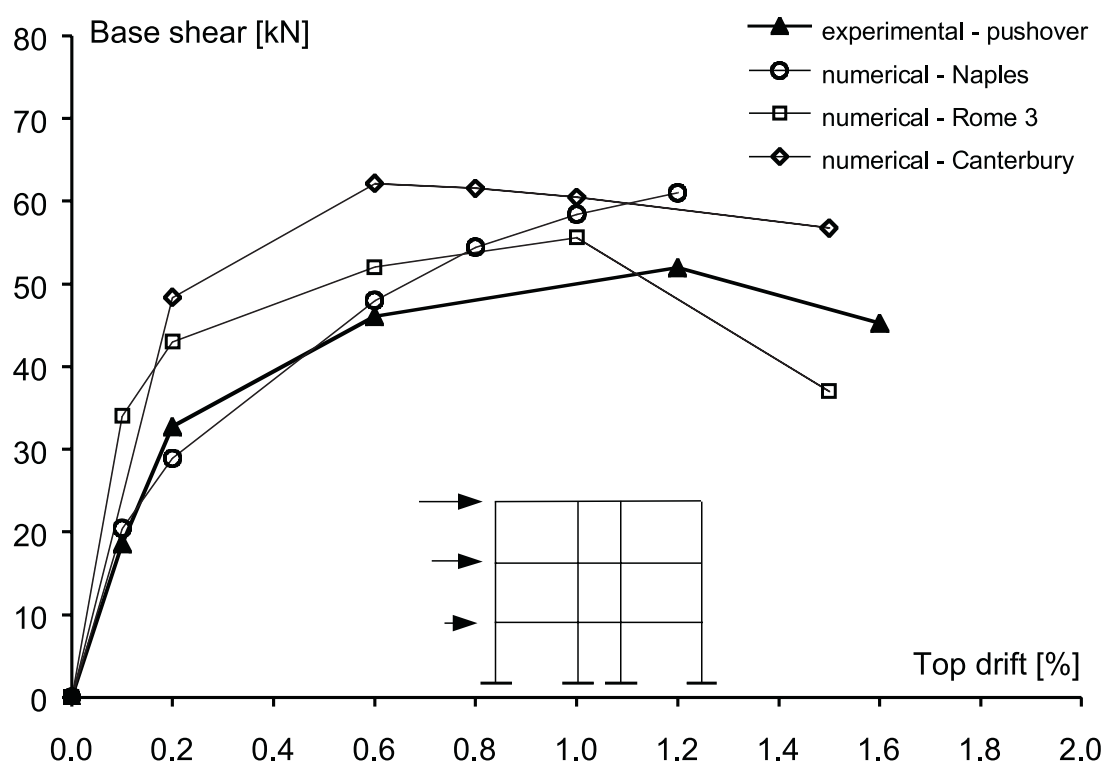

Fig. 6. Blind prediction of the Pavia test results.

failures, this method also determines failures characterised by low ductility due to the bendingshear interaction.

The model for infill walls is based on the shear model by (Fardis and Panagiokatos, 1997). It takes into account the strength reduction due to the cracking of the panels and the post-strength degradation. It is based on four different steps: initial shear behaviour of the uncracked panel, behaviour of the cracked panel as equivalent strut, its instability after the maximum strength and final stage after complete failure characterised by constant residual strength (fig. 5).

The proposed model was validated using different comparison with experimental tests. In fig. 6 a blind prediction of the Pavia test (Pampanin et al., 2001) is drawn, where is possible to appreciate its effectiveness (Cosenza et al., 2002b).

\section{The behaviour of a critical detail: the hook anchorage}

The anchorage of reinforcing steel in RC joint is a critical detail in the behaviour of under- designed structures, especially when smooth rebars are used. In the following the research process for the implementation of the corresponding element in the model is described as example of the development of the numerical tool.

As a first step, an exstended experimental program was performed to characterize the behaviour of straight rebars and hooked ends. The experimental program is divided into two phases, depending on the type of tests: beamtest for evaluation of bond properties of straight bars and service performances of hooked anchorages; pull-out tests to analyse the response of hooked anchorages both under service and ultimate load (fig. 7a,b). The first phase is characterised by 10 tests, 6 straight bars and 4 hooked anchorages, the main investigated parameter is the bar diameter, 12 and $16 \mathrm{~mm}$, derived from the above mentioned review of design practice (Fabbrocino et al., 2002a).

The second phase is characterised by a more comprehensive set of investigated parameters: bar diameter, cast direction, concrete cover thickness, orientation of hooks and the type of 


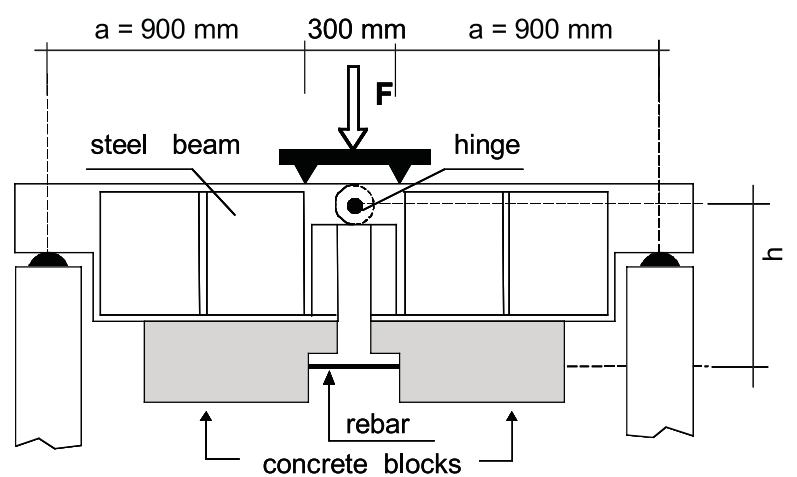

(a)

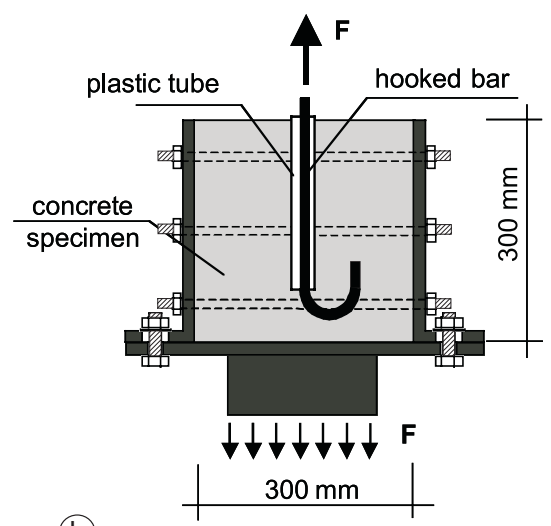

(b)

Fig. 7a,b. Test setup: a) beam-test and b) pull-out.

loading (monotonic or cyclic); at the present stage more than 20 tests have been carried out (Fabbrocino et al., 2002b).

In the following, an overview of the experimental results is reported to discuss the main aspects of load-slip behaviour of anchored smooth bars. Reinforcements used are smooth rebars that are still available for secondary purposes in RC structures and have mechanical properties similar to steel classified as Aq. 42 according to Italian design Code of '60s; yielding stress is about $320 \mathrm{MPa}$, ultimate strain is equal to $430 \mathrm{MPa}$ and ultimate uniform strain is about $20 \%$. Concrete was prepared according to typical mix rules of the ' $60 \mathrm{~s}$ and tests on cubes $150 \mathrm{~mm}$ wide are used to define mean concrete strength. In the following, an overview of experimental results is presented.

Figure 8a summarizes the results of beam tests on straight bars. The shape of the bond stress-slip relationship points out that mechanical interaction is characterised by different phases, like the initial adhesion, and the final residual strength related basically to friction mechanisms. The bond stress for $16 \mathrm{~mm}$ rebars is about 2.35 $\mathrm{MPa}$ reached at a slip of about $0.20 \mathrm{~mm}$; for 12 $\mathrm{mm}$ the values are $2.10 \mathrm{MPa}$ and $0.07 \mathrm{~mm}$ respectively.

Some experimental results of modified pullout tests are reported in fig. $8 \mathrm{~b}$. The figure describe the mechanical behaviour of circular hooks and shows all the measured parameters.

The tests are carried out up to bar failure, that is reaching strains higher than $20 \%$, both bar strain-hook slip and stress-slip relationship for hooked anchorage show that the slip of the hook at yielding is constant and slip increases when strain-hardening is activated. Furthermore, initial stiffness of the hook stress-slip relationship is very high, and even a stress range with no slip exists.

A significant slip is obtained at bar yielding; it ranges between 0.80 and $2.49 \mathrm{~mm}$ and cannot be easily neglected when the deformation capacity of the anchored bar is concerned. This value increases when strain hardening is triggered and becomes about $8 \mathrm{~mm}$ at failure.

After these, a numerical model was developed starting from the experimental results. The structural behaviour of straight bars anchored with hooks can be described using two different components: the straight part of bar, that is governed by the steel-concrete bond, and the hooked part, that presents a mechanical interaction with the concrete.

This approach is briefly described in fig. 9, where the bond slip relationship is introduced for the straight part, while a specific force-slip relation, obtained from the experimental results, is introduced for the hook. 


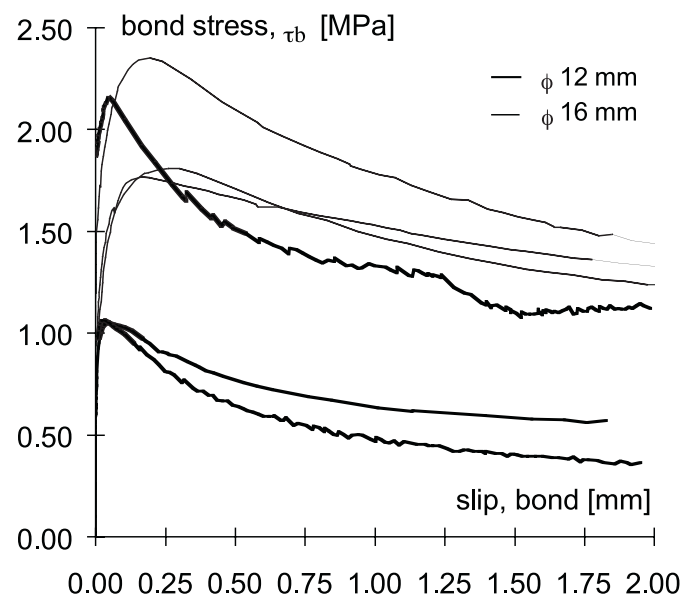

(a)

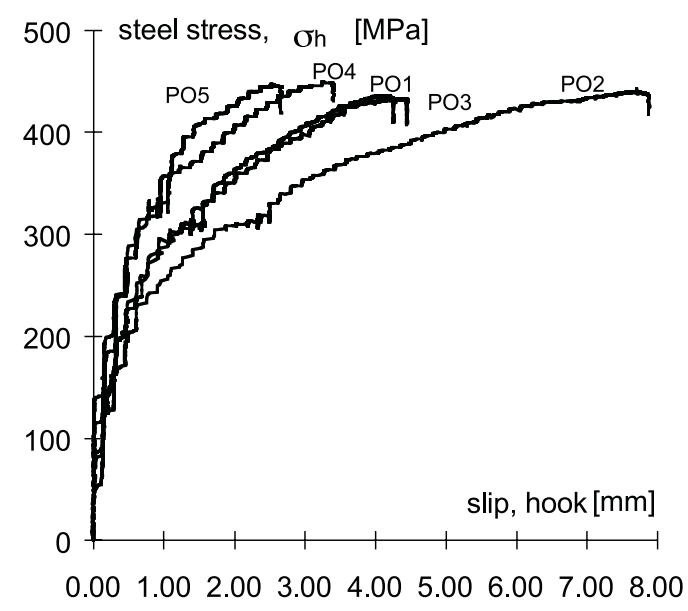

(b)

Fig. 8a,b. Test results: a) bond stress-slip in the straight rebars; b) bond stress-slip in the hooked rebars.

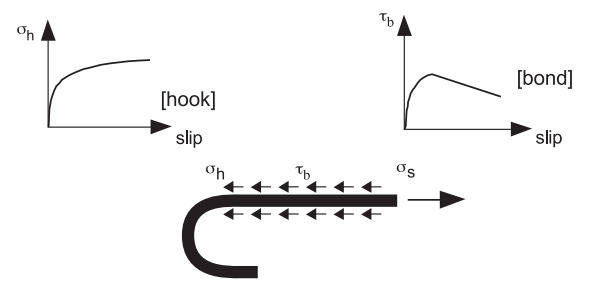

Fig. 9. Element for the hooked rebars.

\section{Buildings characteristics: in situ investigations in Catania}

A first application of the proposed strategy was made in Catania, where a large part of the city has been studied, defining different urban sectors, with homogeneous buildings characteristic in terms of structural typology and age of construction. Particular attention has been devoted to reinforced concrete buildings constructed in the '60s and '70s.

In each urban sector, a field survey of the buildings was performed, filling appropriate forms for each structure, that contains geometrical and mechanical data; this step is coupled with the acquisition of original design draw- ings and reports. The data are enriched with information based on regulations and practise rules used during the construction age and interview with practitioners and contractors: the results of this step is the definition of homogeneus classes of buildings representing typical structures.

The elaboration of the data, related to an urban area examined in Catania, showed that the majority of buildings have a rectangular plan and in particular the most common dimensions in the plan are about $40 \times 10$ square meters with three or four floors: a reference building has been chosen as representative of this class. In this particular application, the representative structure is similar to an existing building that was then assumed as typical building for the seismic assessment (Mollaioli and Verderame, 2000); in other words, the representative building was an existing structure.

The building, described in the following, is representative of a structural typology very common in Catania in the ' 70 s before the seismic classification and, therefore, it was designed only for gravity load. It is a four floor RC framed building with a rectangular plan with a transverse axis of symmetry; three floors are above the ground, the fourth is under ground. The di- 


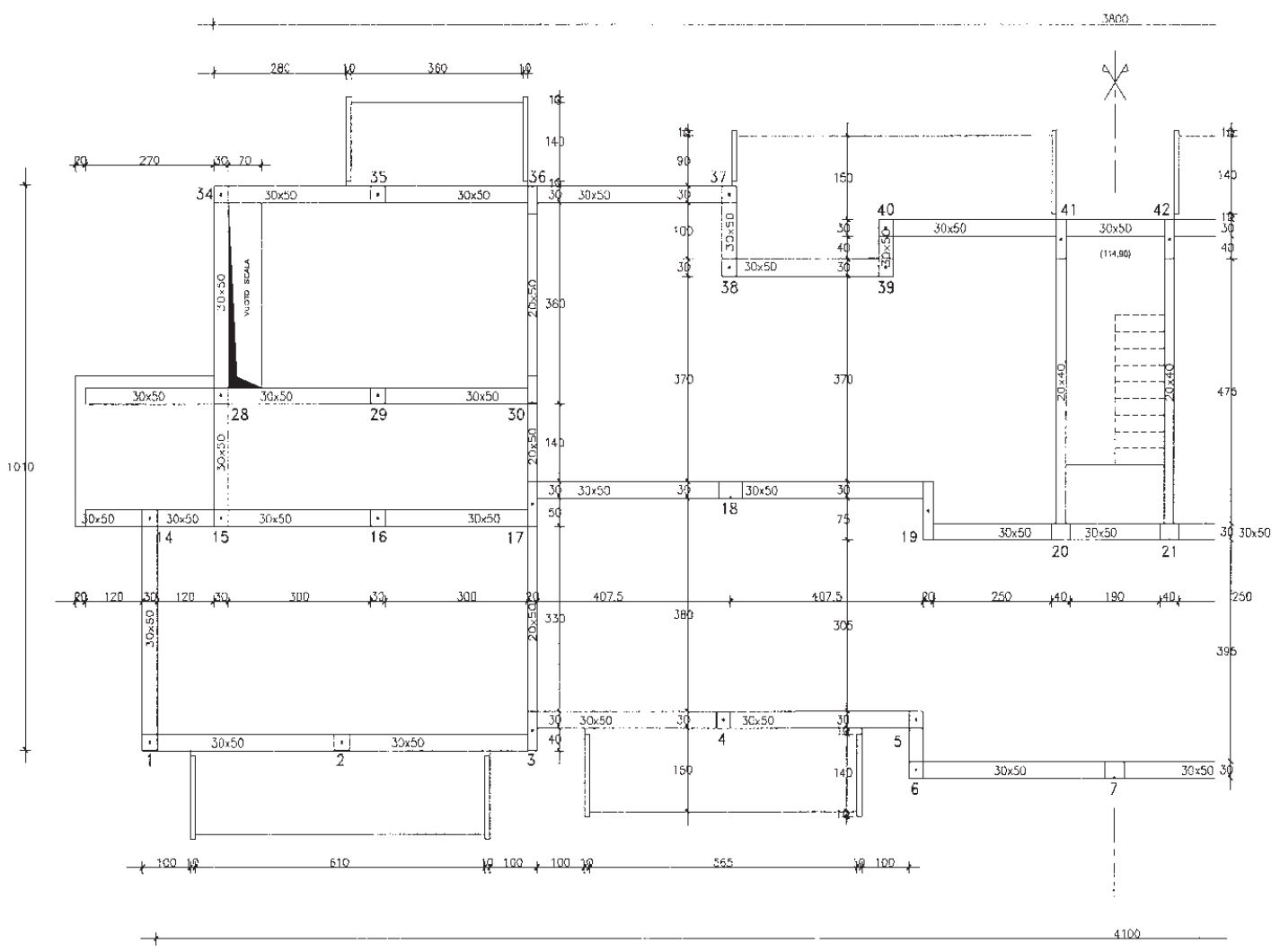

Fig. 10. Geometry of the Catania building: plane view.

mensions of its plan are $41 \times 10 \mathrm{~m}$, while its height is equal to about $12 \mathrm{~m}$ (fig. 10). Three floors have similar plan, while the fourth has a smaller area; its function is to cover the stairs volume and is neglected in the analysis. The columns distribution in the plan is quite regular; their dimensions range from a minimum of $30 \times 50 \mathrm{~cm}$ to a maximum of $20 \times 105 \mathrm{~cm}$; the exterior beams have dimensions of $30 \times 50 \mathrm{~cm}$ with a slab 20 $\mathrm{cm}$ thick. The geometric dimensions of the elements, the steel percentages, the structural masses and loads have been obtained from the original drawings. The constitutive relationship for the steel was introduced considering the average mechanical parameters obtained in the statistical analysis described in Section 3; as regards the strength, it has been assumed that concrete and steel strength were equal to the design values of $f_{c}^{\prime}=25 \mathrm{MPa}$ and $f_{y}=380 \mathrm{MPa}$, respectively.

\section{Assessment of the seismic capacity of the Catania building}

The seismic assessment of the reference building was developed following the ATC40 (ATC, 1996) and the SEAOC (1998) procedures. The seismic capacity was evaluated using a pushover analysis. The push-over analysis was conducted using the numerical model mentioned above, which gives a reliable estimate of the contribution of the different mechanisms to the global behaviour, starting from the constitutive relationships of the materials. The push-over analysis was carried out on the analyzed structure 
applying a pre-defined distribution of horizontal forces; in particular, the distribution was selected for the structure to respect the first mode of vibration. The analysis was conducted considering a 2D approach that is justified by the regularity in plan of the structures that minimizes torsional effects. The structural collapse of the reinforced concrete frame was achieved in a base column due to concrete crushing. Figure 11 depicts the push over curve.

Using the method proposed by Fajfar and Gaspersic (1996), the equivalent SDOF is calculated starting from the capacity curve obtained from the push over analysis and assuming a displacement shape indipendent on the drift level: in this case a displacement shape similar to the first mode of vibration is assumed.

The dynamic properties of equivalent SDOF in terms of base shear $V_{\text {eq }}$ and mass $M_{\text {eq }}$ can be defined starting from the corresponding properties of the MDOF and the capacity curve can be obtained scaling the base shear-drift relationship obtained for the multistory structure.
The definition of the equivalent SDOF requires a linearization procedure of the push over curve that must be fitted with a bilinear curve, defined by the initial and the post-yielding stiffness. The linearization procedure also, defines the yielding strength and the ultimate ductility of the equivalent SDOF.

In this case, the procedure suggested by Fajfar assumes that the initial stiffness of the equivalent system is equal to $50 \%$ of the stiffness of the MDOF system, while the postyielding stiffness is assumed equal to $5 \%$ of the initial stiffness. Table V summarizes the elastic period, the shear strength, the mass and the equivalent ductility obtained in the linearization procedure.

The results were then compared with the inelastic spectra obtained using the synthetic

Table V. Dynamic properties of the equivalent SDOF for the Catania building.

\begin{tabular}{cccl}
\hline \hline$T_{\text {eq }}[s]$ & $V_{\text {eq }}[\mathrm{kN}]$ & $M_{\text {eq }}\left[\mathrm{kNs}^{2} / \mathrm{m}\right]$ & $\mu$ \\
\hline 0.86 & 590 & 709 & 4.42 \\
\hline
\end{tabular}

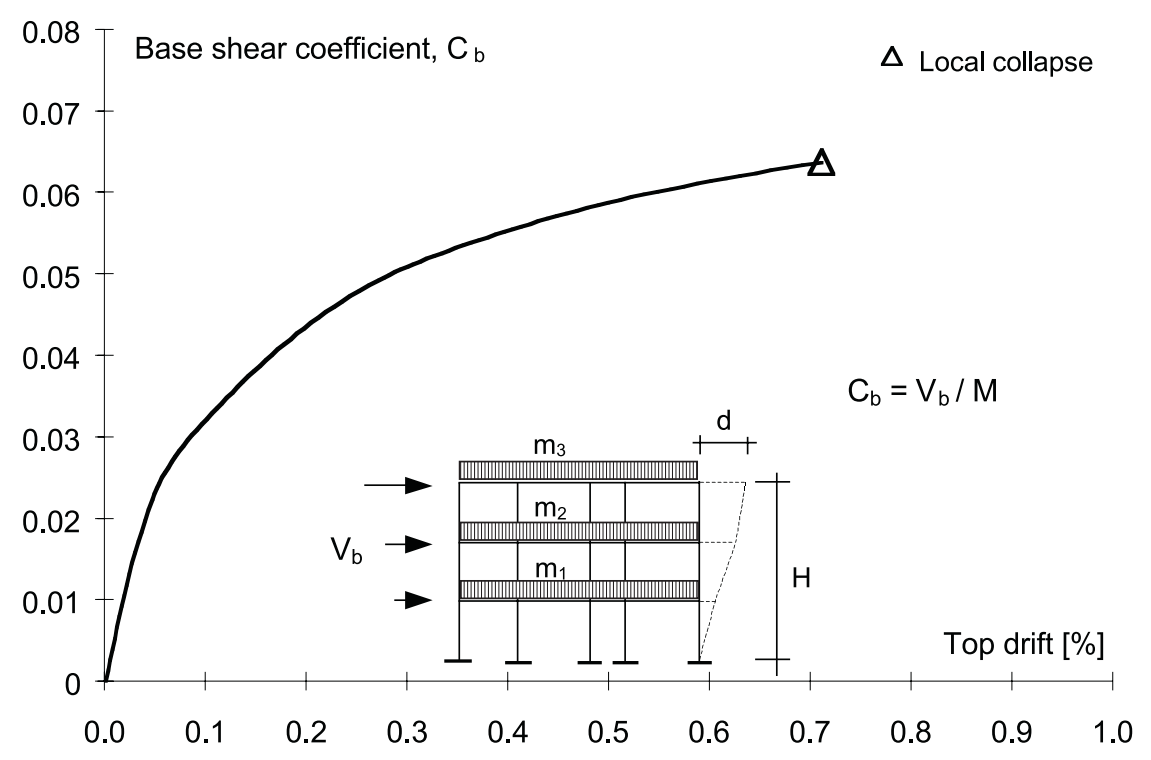

Fig. 11. Push-over analysis of the Catania building. 


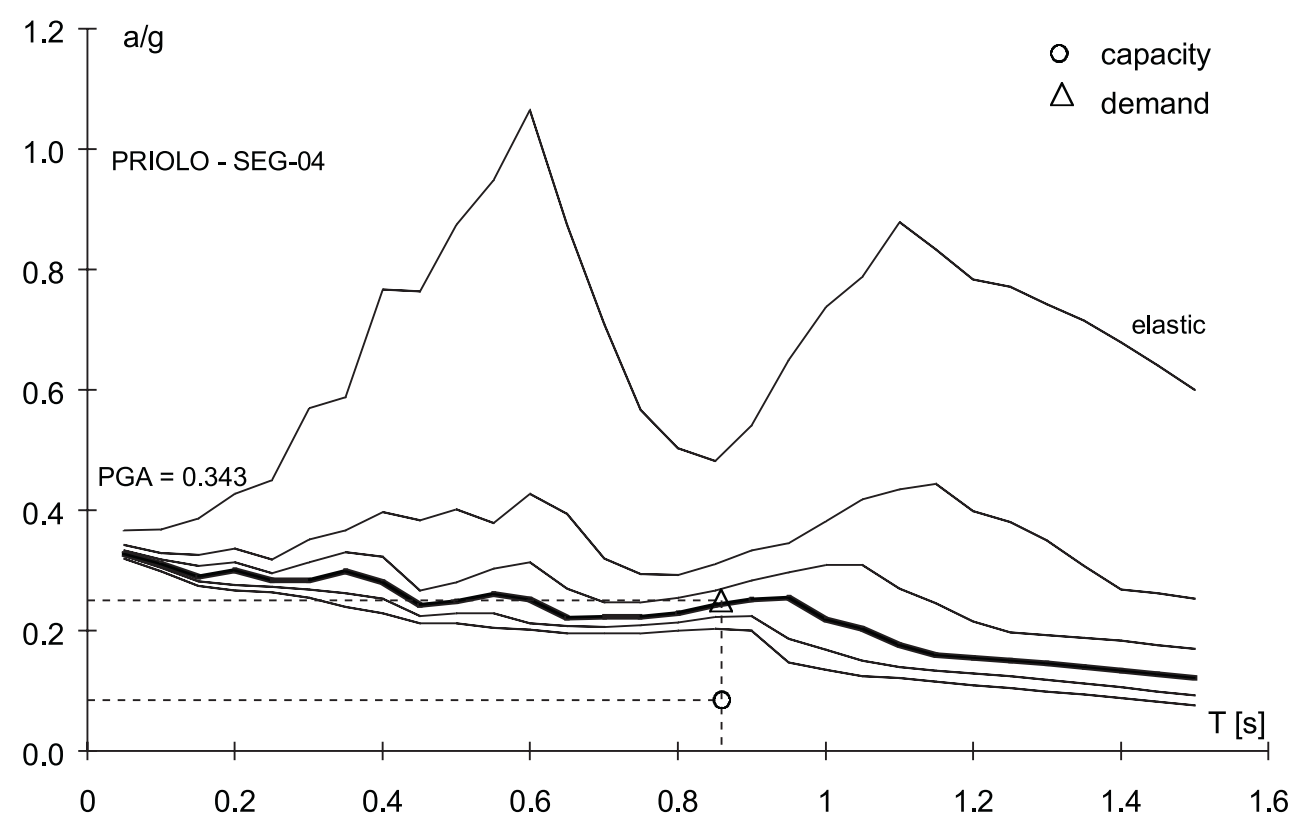

Fig. 12. Spectral analysis of the Catania building. Elastic spectra and inelastic strenght spectra for fixed ductilities; thick line corresponds to $\mu=4.42$.

records generated by Priolo (1999) for the destructive earthquake with a return period of 475 years expected in Catania (fig. 12).

The capacity of the structure is much lower than the expected actions. In order to obtain a demand comparable with the capacity it is necessary to reduce in average the expected records by about three times.

\section{Conclusions}

The assessment strategy presented in this paper is a procedure in progress that is continuously developed and refined considering experiences from field applications. The key issue of the procedure is the integration of information based on filed survey, regulations, practic rules used during the construction age, and interviews with practitioners and contractors.

The method seems promising particularly for urban areas characterized by RC underdesigned buildings, in which all the brittle mechanisms can potentially play an important role and consequently refined numerical tools are required for a reliable assessment of the seismic capacity.

The application to the city of Catania evidences the potential of the procedure to achieve a quantitative assessment of the seismic capacity of RC underdesigned structures and shows their low capacity in comparison to seismic demand.

\section{REFERENCES}

ATC (1996): Seismic Evaluation and Retrofit of Concrete Buildings, Applied Technology Council (Rep. n. ATC 40), Redwood City, California.

BIA (1996): The Assessment and Improvement of the Structural Performance of Earthquake Risk Buildings, New Zealand National Society for Earthquake Engineering, June 1996, pp. 122.

BragA, F., M. DolCE and D. Liberatore (1982): A statistical study on damaged buildings and an ensuing review of the MSK-76 scale, in 7th European Conference on Earthquake Engineering, Athens, 1982.

CALVI, G.M. (1999): A displacement-based approach for vulnerability evaluation of classes of buildings, $J$. Earthquake Eng., 3 (3), 411-438. 
CENSIS (1999): XXXII Rapporto sulla Situazione Sociale del Paese (F. Angeli Ed., Milano), pp. 653.

CosenZA, E. and G. MANFrEdi (1997): Some remarks on the evaluation and strengthening of underdesigned RC frame buildings, Technical Report, NCEER-97-0003, State University of New York at Buffalo, 157-175.

Cosenza, E., G. MANFredi and G. Verderame (1999): Seismic assessment of RC structures: case studies in Catania, in The Catania Project: Earthquake Damage Scenarios for High Risk Area in the Mediterreaneam, edited by E. FACCIOLI and V. PESSINA, CNR, Gruppo Nazionale per la Difesa dei Terremoti, Roma, pp. 255.

CosenZA, E., G. MANFREDI and G.M. Verderame (2002a): A nonlinear model for underdesigned RC frames, in Twelfth European Conference on Earthquake Engineering, London, September 2002.

Cosenza, E., G. MANFrEdi and G.M. VERDERAME (2002b): Seismic assessment of gravity load designed RC frames: critical issues in structural modeling, J. Earthquake Eng., 6. Special Issue 1, 101-122.

De Marco, R., M.G. Martini, G. Di Pasquale, A. FRALLEONE and A.G. PIZZA (2000): La Classificazione Sismica e la Normativa Sismica Italiana dal 1909 al 1984, Servizio Sismico Nazionale.

Eurocode 8 (1995): Design Provisions for Earthquake Resistance of Structures, Strengthening and Repair of Buildings, ENV 1998 1-4, CEN, Brussels.

FABBROCINO, G., G. VERDERAME and G. MANFREDI (2002a): Experimental behaviour of straight and hooked smooth bars in existing RC buildings, in Twelfth European Conference on Earthquake Engineering, London, September 2002.

Fabbrocino, G., G. Verderame, G. Manfredi and E. COSENZA (2002b): Experimental behaviour of smooth bars anchorages in existing RC buildings, in Osaka
Congress, 13-19 October 2002, Osaka, Japan.

FAJFAR, P. and P. GASPERSIC (1996): The N2 Method for the seismic of RC buildings, Earthquake Eng. Struct. Dyn., 25, 31-46.

FARdis, M.N. and T.B. Panagiotakos (1997): Seismic design and response of bare and masonry-infilled reinforced concrete buildings - Part II: infilled structures, J. Earthquake Eng., 1 (3), 475-503.

Mollaioli, F. and G.M. Verderame (2000): Caratteristiche degli edifici campione situati nell'area di Catania, in Comportamento Sismico di Edifici in Cemento Armato Progettati per Carichi Verticali, edited by E. CosENZA, CNR, Gruppo Nazionale per la Difesa dei Terremoti, Roma, Dicembre 2000, pp. 201.

Pampanin, S., G.M. Calvi and G. Magenes (2001): Experimental test on a three storey reinforced concrete frame designed for gravity only, Internal Report.

PRIESTLEY, M.J.N., R. VERMA and Y. XIAO (1994): Seismic shear strength of reinforced concrete columns, ASCE, J. Struct. Eng., 120 (8), 2310-2329.

PRIOLO, E. (1999): 2D spectral element simulation of destructive ground shaking in Catania (Italy), J. Seismol., 3 (3), 289-309.

SEAOC (1998): Part 2, Preliminary Guidelines for Performance Based Seismic Engineering a ForceDisplacement Approach.

VERDERAME, G.M., G. MANFREDI and G. FRUNZIO (2001a): Le proprietà meccaniche dei calcestruzzi impiegati nelle strutture in cemento armato realizzate negli anni ' 60 , in $X$ Convegno Nazionale «L'Ingegneria Sismica in Italia», Potenza e Matera, 9-13 Settembre 2001.

Verderame, G.M., A. STELla and E. Cosenza (2001b) Le proprietà meccaniche degli acciai impiegati nelle strutture in cemento armato realizzate negli anni '60, in X Convegno Nazionale «L'Ingegneria Sismica in Italia», Potenza e Matera, 9-13 Settembre 2001. 